\title{
COPD phenotypes in biomass smoke- versus tobacco smoke-exposed Mexican women
}

\author{
Pat G. Camp ${ }^{1,2,8}$, Alejandra Ramirez-Venegas ${ }^{3,8}$, Raul H. Sansores ${ }^{3}$, Luis F. Alva , \\ Jill E. McDougall', Don D. Sin ${ }^{1,5}$, Peter D. Paré ${ }^{1,5}$, Nestor L. Müller ${ }^{6}$, \\ C. Isabela S. Silva ${ }^{7}$, Carlos E. Rojas ${ }^{4}$ and Harvey O. Coxson ${ }^{1,6}$
}

\begin{abstract}
Affiliations: ${ }^{1}$ James Hogg Research Center, University of British Columbia, St Paul's Hospital, Vancouver, BC, ${ }^{2}$ Dept of Physical Therapy, University of British Columbia, Vancouver, BC, ${ }^{5}$ Dept of Medicine, University of British Columbia, Vancouver, BC, and 'Dept of Radiology, University of British Columbia, Vancouver, BC, Canada. ${ }^{3}$ Departamento de Investigación en Tabaquismo y EPOC, Instituto Nacional de Enfermedades Respiratorias Ismael Cosio Villegas, Mexico City, and “Unidad de Radiología e Imágen, Hospital Medica Sur, Mexico City, Mexico. ${ }^{7}$ Dept of Radiology, Clinica Delfin and Portuguese Hospital, Salvador, Brazil. ${ }^{8}$ Both authors contributed equally.
\end{abstract}

Correspondence: P.G. Camp, UBC James Hogg Research Centre, St Paul's Hospital, 1081 Burrard Street, Vancouver, BC, V6Z 1Y6, Canada. E-mail: pat.camplahli.ubc.ca

ABSTRACT We hypothesised that biomass smoke exposure is associated with an airway-predominant chronic obstructive pulmonary disease (COPD) phenotype, while tobacco-related COPD is associated with an emphysema-predominant phenotype.

In this cross-sectional study, female never-smokers with COPD and biomass exposure $(\mathrm{n}=21)$ and female ex-cigarette smokers with COPD without biomass exposure $(n=22)$ completed computed tomography (CT) at inspiration and expiration, pulmonary function, blood gas, exercise tolerance, and quality of life measures. Two radiologists scored the extent of emphysema and air trapping on CT. Quantitative emphysema severity and distribution and airway wall thickness were calculated using specialised software.

Women in the tobacco group had significantly more emphysema than the biomass group (radiologist score 2.3 versus $0.7, p=0.001$; emphysema on CT $27 \%$ versus $19 \%, p=0.046$; and a larger size of emphysematous spaces, $\mathrm{p}=0.006$ ). Women in the biomass group had significantly more air trapping than the tobacco group (radiologist score 2.6 and 1.5, respectively; $\mathrm{p}=0.02$ ) and also scored lower on the symptom, activities and confidence domains of the quality of life assessment and had lower oxygen saturation at rest and during exercise $(\mathrm{p}<0.05)$.

Biomass smoke exposure is associated with less emphysema but more air trapping than tobacco smoke exposure, suggesting an airway-predominant phenotype.

@ERSpublications

Biomass smoke causes less emphysema but more air trapping than tobacco smoke: airwaypredominant COPD phenotype? http://ow.ly/rHdju

For editorial comments see page 659 .

Received: Dec 212012 | Accepted after revision: May 152013 | First published online: Oct 102013

Conflict of interest: Disclosures can be found alongside the online version of this article at www.erj.ersjournals.com

Copyright @ERS 2014 


\section{Introduction}

Biomass smoke is a risk factor for the development of airflow obstruction and chronic obstructive pulmonary disease (COPD), especially in developing countries [1-4]. Approximately $50 \%$ of the world's population uses biomass fuels for cooking, light and heat, often in dwellings where ventilation is poor. The clinical characteristics of COPD associated with exposure to biomass smoke have been well described. RAMìrEZ-VENEGAS et al. [5] reported that COPD patients exposed to biomass smoke were more likely to be female, with similar symptoms, exercise capacity, quality of life and need for supplementary oxygen, yet have less severe airflow obstruction than tobacco smokers with COPD.

There are two major phenotypes of COPD, bronchiolitis (also referred to as "small airways disease") and emphysema. In tobacco-related COPD, the two phenotypes generally co-exist in variable proportions. Little is known about biomass-related COPD phenotypes because COPD pathophysiology related to biomass smoke is poorly understood. In a study of human lung tissue from autopsy, RiverA et al. [6] found that the lungs of individuals who were exposed to wood smoke demonstrated more severe bronchiolitis and less emphysema. Details on lung disease diagnosis or other clinical characteristics of these patients were not available. It is not known if similar findings would be detected in living patients with confirmed COPD.

In vivo assessment of COPD phenotypes is now possible with the advent of multidetector computed tomography (MDCT) scanning. This technology has made the investigation of the site, magnitude and distribution of parenchymal destruction, gas trapping, airway remodelling and airway narrowing possible. We hypothesised that biomass smoke exposure is associated with an airway-predominant phenotype of COPD, with increased air trapping and airway wall thickness, while tobacco-related COPD would be associated with an emphysema phenotype.

\section{Methods}

\section{Study setting}

This was a cross-sectional comparison of two groups of women with COPD who had comparable airflow obstruction but different exposure histories. The study was performed in the COPD clinic of the Instituto Nacional de Enfermedades Respiratoris Ismael Cosio Villegas (INER) in Mexico City, Mexico. This facility is a public tertiary care centre that focuses on medical care, teaching and research, and provides healthcare services to the economically deprived population of Mexico. The study was approved by the ethical review boards at INER (Comite de Ciencia y Bioetica en Investigacion C08-05), and the University of British Columbia (Providence Health Care H07-00095) in Vancouver, Canada. All participants provided written, informed consent. This study was funded by the research programme at INER (patient recruitment, testing and technical support) and by GlaxoSmithKline Canada and the Canadian Institutes of Health Research (computed tomography (CT) scan acquisition and analysis).

\section{Diagnosis of COPD}

We recruited participants from a cohort of female patients with COPD from INER. Eligible participants were aged between 40 and 80 years, had post-bronchodilator spirometric evidence of COPD (forced expiratory volume in $1 \mathrm{~s}$ (FEV1)/forced vital capacity (FVC) ratio $<0.70$ and FEV1 $<80 \%$ predicted) and past exposure to either biomass smoke or tobacco smoke. Women with biomass smoke exposure had never smoked cigarettes and had $\geqslant 6$ months of daily biomass smoke exposure, but were not currently exposed. Female participants with tobacco smoke exposure had $\geqslant 10$ pack-years of smoking history, were exsmokers and had never been exposed to biomass smoke. Participants were exacerbation free for $\geqslant 1$ month. Each biomass-smoke exposed woman was matched by age (within 5 years) and post-bronchodilator FEV1 $\%$ pred (within 10\%) to a woman exposed to cigarette smoke, to reduce the impact of confounding factors.

Support statement: This study was funded by a non-restricted research grant from GlaxoSmithKline Canada, a Canadian Institutes of Health Research Interdisciplinary Capacity Enhancement: Bridging Excellence in Respiratory Disease and Gender Studies (ICEBERGS) team grant, and internal research funds held at the Instituto Nacional de Enfermedades Respiratorias Ismael Cosio Villegas (Mexico). At the time of this study, P.G. Camp was funded by a Canadian Institutes of Health Research Fellowship, a Canadian Respiratory Health Professional Fellowship, and a trainee award from ICEBERGS. She is currently a Michael Smith Foundation for Health Research Clinical Scholar. H.O. Coxson was a CIHR/ British Columbia Lung Association New Investigator and is currently funded in part by Pittsburgh Chronic Obstructive Pulmonary Disease (COPD) Specialized Centers of Clinically Oriented Research (SCCOR) NIH 1P50 HL084948 and R01 HL085096 from the National Heart, Lung, and Blood Institute at the National Institutes of Health to the University of Pittsburgh and the British Columbia Lung Association Robert R. Miller Fellowship in Thoracic Imaging. D.D. Sin holds the Canada Research Chair in COPD. P.D. Paré is a Michael Smith Foundation for Health Research Distinguished Scholar and the Jacob Churg Distinguished Researcher. 


\section{Outcomes}

Smoke exposure was determined by the standardised Spanish version of the American Thoracic Society (ATS) questionnaire [7] supplemented by questions related to cooking fuels. The questions related to exposure to biomass fuels are presented in the online supplementary material. Cumulative exposure to biomass was expressed as hour-years, calculated by multiplying the number of years cooking with wood stoves by the average daily hours spent in the kitchen.

Participants underwent pre- and post-bronchodilator spirometry with a dry rolling seal volume spirometer (Sensormedics, Yorba Linda, CA, USA) and plethysmographic lung volume measurements following the procedures recommended by the ATS. We used Mexican standard reference equations for predicted values of FEV1 and FVC [8], which are similar to the third National Health and Nutrition Examination Survey values for Mexican-Americans. Arterial blood gas samples were taken at rest on room air. Mexico City's mean altitude is $2240 \mathrm{~m}$ above sea level. In Mexico City, normal mean arterial oxygen tension $\left(\mathrm{PaO}_{2}\right)$ and carbon dioxide tension $\left(\mathrm{PaCO}_{2}\right)$ values in young subjects are $66-72 \mathrm{mmHg}$ and $28-32 \mathrm{mmHg}$, respectively, and arterial oxygen saturation measured by pulse oximetry $\left(\mathrm{S}_{\mathrm{PO}_{2}}\right)$ values are typically $95-96 \%$.

Each participant completed a 6-min walk test and the distance walked was calculated [9]. We measured $\mathrm{SpO}_{2}$ and heart rate using a pulse oximeter and dyspnoea using the Borg scale [10], at rest and at the end of the walk test. Subjects also completed the modified Medical Research Council (mMRC) Dyspnoea Scale [11], the St George's Respiratory Questionnaire (SGRQ) [12] and the Chronic Respiratory Questionnaire (CRQ) [13] translated into Spanish.

The MDCT scans were performed at suspended full inspiration and expiration $(120 \mathrm{kVp}, 90 \mathrm{mAs})$ on a multidetector row CT scanner (Sensation 16; Siemens, Forchheim, Germany). Contiguous CT images were reconstructed with a 1-mm slice thickness and a low (b35f) spatial frequency reconstruction algorithm for emphysema measurements, and a high (b65f) spatial frequency reconstruction algorithm for airway measurements. In addition, two radiologists who were blinded to the exposure history of each subject independently scored each scan. Using a six-point scale $(0=$ none to $5=$ extensive $)$, air trapping was scored by comparing inspiratory to expiratory scans, while emphysema was scored with a similar six-point scale using the inspiratory CT scans, as per a similar COPD study [14]. The radiologists also noted the presence or absence of bronchiectasis.

Quantitative assessment of emphysema was performed using custom software (EmphylxJ, Vancouver, Canada). For emphysema, we calculated the percentage of the parenchyma $<-950 \mathrm{HU}$ (\% low attenuation area (\%LAA)) on the inspiratory CT scans [15]. We estimated the size of the emphysematous spaces using low attenuation cluster analysis. This analysis calculates the relationship between the number of low attenuation voxels and how those voxels are connected to each other [16]. The slope of the relationship between the number and grouping of low attenuation areas (D) (log-log plot) has a smaller value if the low attenuation voxels are clustered into larger emphysematous spaces.

Quantitative assessment of airway wall dimensions was performed using the full width at half maximum method [17]. The internal lumen perimeter (pi), the lumen area (Ai) the wall area (Aaw) and the percentage of the airway occupied by the wall (wall area percentage $(\mathrm{WA} \%)=\mathrm{Aaw} / \mathrm{Ai}+\mathrm{Aaw} \times 100)$ ) were calculated on airways cut in cross-section. To standardise airway wall measurements between subjects and reduce the bias of airway sampling, we created a regression equation to determine the square root of the wall area at a lumen perimeter of $10 \mathrm{~mm}$ (SQRTWA-pi10) for each subject [14]. Air trapping was quantified by measuring the percentage of the parenchyma $<-856 \mathrm{HU}$ [18] on the expiratory CT scans (\%LAA $<856 \mathrm{HU}$ at expiratory scan). We also calculated the ratio of the mean lung density on the expiratory scan to the mean lung density on the inspiratory scan (CT/lung density ratio). This measurement has been reported previously by METs et al. [19] as "CT-air trapping".

\section{Statistical analysis}

The baseline characteristics of the subjects were described using mean $\pm \mathrm{SD}$. Initial comparisons were made using a t-test for normally distributed data, or the Mann-Whitney U-test for non-normally distributed data. Using multiple linear regression models, we also calculated the relationship between exposure group and the emphysema variables (\%LAA $<950 \mathrm{HU}$ at inspiratory scan, D, or radiologist score of emphysema) and between exposure group and airways disease variables (SQRTWA_pi10, WA\%, \%LAA <856 HU at expiratory scan, radiologist score of air trapping and CT-air trapping), adjusting for age and postbronchodilator FEV1 \% pred. Height was also entered into all models due to the differences in height between groups. SAS 9.3 (SAS Institute Inc., Cary, NC, USA) was used for all analyses. 


\section{Results}

\section{Patient characteristics}

Of the 173 female participants with COPD in the respiratory clinic cohort, 52 tobacco smoke-exposed and 53 biomass smoke-exposed participants met the study criteria (fig. 1). Of these, 22 participants in each group were matched by post-bronchodilator FEV1 \% pred and age. One participant in the biomass group was subsequently removed from the analysis as she did not have a post-bronchodilator FEV1/FVC $<0.70$ at the time of data collection. There were no significant differences between the two groups with respect to: age; post-bronchodilator FEV1 \% pred, FVC \% pred or FEV1/FVC ratio; lung volumes; weight; or body mass index (table 1), although participants in the tobacco group were taller. The mean cumulative exposure for the biomass group was 275 hour-years, which is equivalent to a daily exposure history of $8 \mathrm{~h} \cdot \mathrm{day}^{-1}$ for 34 years. Participants in the biomass group reported that biomass smoke exposure had mainly occurred during cooking activities. In addition, $76 \%$ of the participants had used only wood, plant material and/or manure for fuel, $14 \%$ had used only charcoal, and $10 \%$ had used both charcoal and plant material. The majority of participants in both groups were at level 2 of the Global Initiative for Chronic Obstructive Lung Disease (GOLD) [20] disease severity scale.

\section{Quality of life, arterial blood gas and functional exercise capacity}

Although the mMRC dyspnoea score was similar in both groups, the scores from the quality-of-life questionnaires indicated that participants in the biomass group reported significantly more symptoms, more activity limitation and less control over their disease (table 2). Although a higher proportion of participants in the biomass group reported cough and sputum symptoms, this was not significant. Most of the participants in both groups were hypoxaemic $\left(\mathrm{PaO}_{2}<60 \mathrm{mmHg}\right)$ at rest (mean $\pm \mathrm{SD} P \mathrm{PO}_{2}$ $49.3 \pm 7.7 \mathrm{mmHg}$ and $52.5 \pm 4.0 \mathrm{mmHg}$ for the biomass group and the tobacco group, respectively). The severity of hypoxaemia is not unexpected, as the values for $\mathrm{PaO}_{2}$ and $\mathrm{PaCO}_{2}$ for the healthy population living at the high altitude of Mexico City are low $(67.7 \mathrm{mmHg}$ and $31.1 \mathrm{mmHg}$, respectively). Participants in the biomass group had a significantly lower arterial oxygen saturation at rest compared to the tobacco group

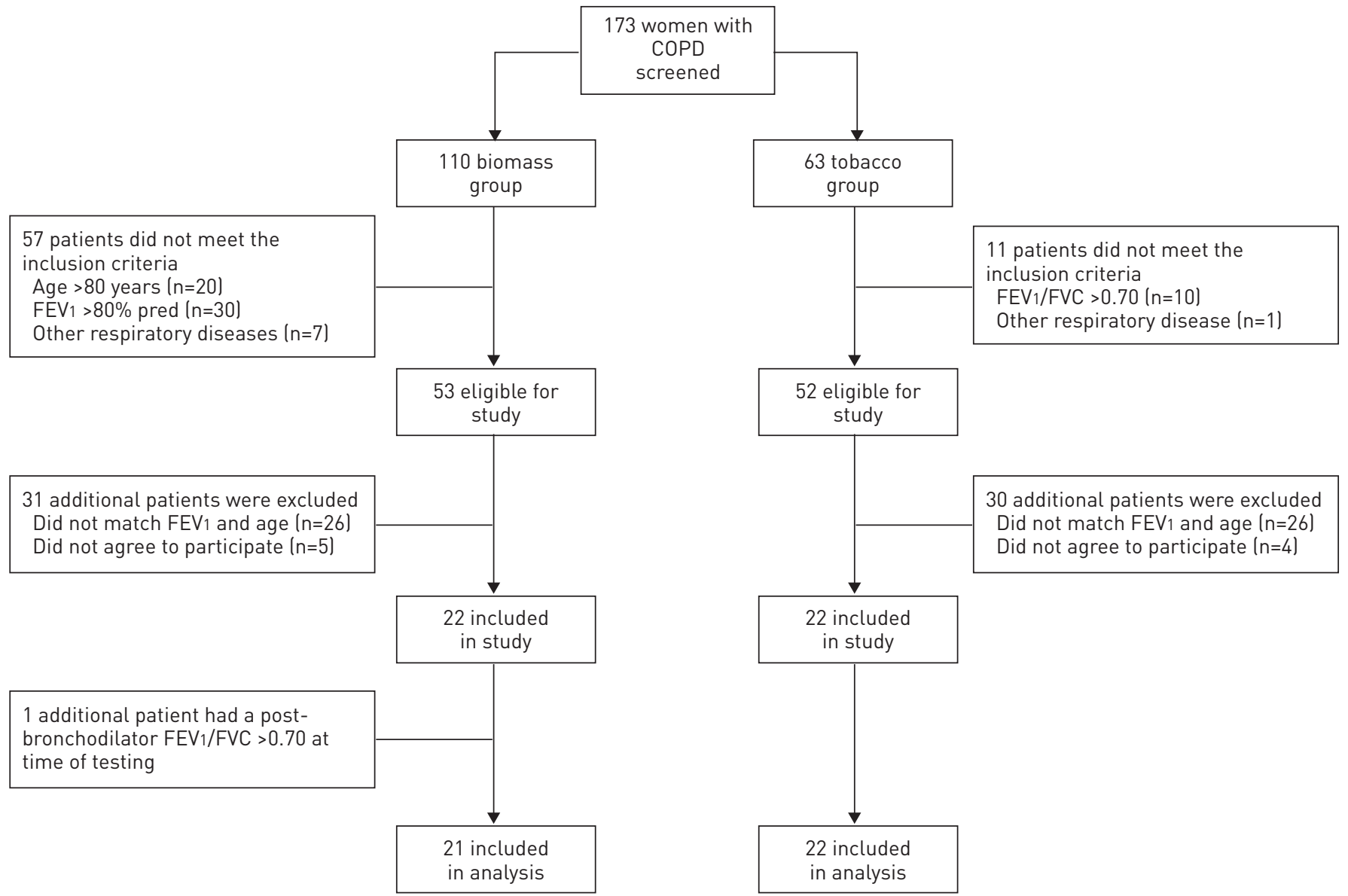

FIGURE 1 Flowchart of subject recruitment. COPD: chronic obstructive pulmonary disease; FEV1: forced expiratory volume in $1 \mathrm{~s}$; FVC: forced vital capacity. 
( $82 \%$ versus $87 \% ; \mathrm{p}=0.01$ ). In addition to a low resting $\mathrm{SpO}_{2}$ both groups had a large drop in $\mathrm{SpO}_{2}$ during the walk test (biomass group $-9.3 \%$; tobacco group $-7.3 \%$; $=0.20$ ).

\section{Emphysema and small airways disease phenotypes}

Women in the tobacco group had more emphysema compared to those in the biomass group, based on both quantitative estimates and radiologists' scoring (tables 3 and 4). Figure 2 shows CT images from women with tobacco and biomass smoke exposure. Figure 2a, from a woman in the tobacco group, shows severe centrilobular emphysema. This finding was corroborated by the radiologists' CT scores as women in the tobacco group had significantly higher scores for emphysema (tobacco group mean score 2.3; biomass group mean score $0.7 ; \mathrm{p}=0.0001$ ). The tobacco group had a greater percentage of emphysema compared to the biomass group (\%LAA $<950 \mathrm{HU}$ at inspiratory scan $27 \%$ versus $19 \%$, respectively; $\mathrm{p}=0.02$ ) and a smaller D-value, indicating larger emphysematous spaces (tobacco group 2.07; biomass group 2.57; $\mathrm{p}=0.002$ ). Adjusting for age, post-bronchodilator $\mathrm{FEV} 1 \%$ pred and height did not alter these results (table 4).

Figure $2 \mathrm{~b}$ shows a representative inspiratory CT image from a participant in the biomass group. The scan shows airway wall thickening and patchy areas of decreased attenuation and vascularity. The radiologists' scoring confirmed that the participants exposed to biomass smoke had significantly higher levels of air trapping than those exposed to tobacco (biomass group air trapping score 2.6; tobacco group air trapping score 1.5), a difference which persisted after adjusting for age, post-bronchodilator FEV1 \% pred and height $(\mathrm{p}=0.022)$ (tables 3 and 4$)$. In addition, the radiologists indicated the presence of bronchiectasis in the scans of $14 \%$ of the participants exposed to biomass smoke compared to $0 \%$ of those exposed to tobacco smoke $(\mathrm{p}=0.009)$. Participants in the biomass group had a lower CT lung density ratio on the univariate analysis; however, there was no difference between the groups in the two quantitative measures of air trapping (\%LAA $<-856 \mathrm{HU}$ on the expiratory CT scans or the CT lung density ratio) or measures of airway thickness on the inspiratory scans (tables 3 and 4) after adjusting for covariates.

\section{Discussion}

In this study we found important structural differences between women with COPD with either biomass or tobacco smoke exposure. We found that participants exposed to biomass smoke had less emphysema, based on both qualitative and quantitative CT measures, than those exposed to tobacco smoke. In addition, less emphysema in the presence of similar airflow obstruction supports the argument that biomass smoke may lead to an airways disease phenotype. Although the quantitative CT scans did not show differences in

TABLE 1 Characteristics of the sample

\begin{tabular}{lcc} 
& Biomass group & Tobacco group \\
\hline Patient characteristics & & 22 \\
Subjects n & 21 & $69.3 \pm 5.5$ \\
Age years & $69.0 \pm 6.3$ & $32.6 \pm 14.4$ \\
Tobacco smoke exposure pack-years & 0 & 0 \\
Biomass smoke exposure hour-years & $275.4 \pm 101.0$ & $154.0 \pm 3.0$ \\
Height cm & $148.0 \pm 6.0$ & $61.9 \pm 10.8$ \\
Weight kg & $61.5 \pm 12.1$ & $26.8 \pm 4.2$ \\
BMI kg-m & $28.5 \pm 6.2$ & 0.90 \\
Lung function & & 0.92 \\
Pre-bronchodilator & & 0.29 \\
FEV1\% pred & $46.7 \pm 14.9$ & $50.3 \pm 12.2$ \\
FVC \% pred & $70.1 \pm 16.3$ & $79.3 \pm 12.8$ \\
FEV1/FVC & $51.9 \pm 12.9$ & $49.3 \pm 10.3$ \\
Post-bronchodilator & & 0.38 \\
FEV1\% pred & $54.5 \pm 14.9$ & 0.05 \\
FVC \% pred & $80.6 \pm 18.6$ & 0.46 \\
FEV1/FVC & $53.2 \pm 11.7$ & $89.0 \pm 11.8$ \\
Lung volumes & & $50.4 \pm 9.7$ \\
RV \% pred & $181 \pm 67$ & $176 \pm 56$ \\
TLC \% pred & $130 \pm 27$ & $125 \pm 21$ \\
RV/TLC \% & $0.66 \pm 0.08$ & $0.62 \pm 0.09$ \\
\hline
\end{tabular}

Data are presented as mean \pm SD, unless otherwise stated. BMI: body mass index; FEV1: forced expiratory volume in 1 s; FVC: forced vital capacity; RV: residual volume; TLC: total lung capacity. ${ }^{*}$ : nonparametric test. 
TABLE 2 Symptoms, quality of life, 6-min walking distance (6MWD) and arterial blood gases

Biomass group

\section{Subjects $\mathrm{n}$ \\ MMRC \\ SGRQ}

Symptoms

Activities

Impact

Total

Report of cough or sputum (from SGRQ)

Subjects $n$

Cough n $(\%)$

Sputum n $(\%)$

Chronic Respiratory Questionnaireף

Dyspnoea

Fatigue

Emotion

Control of disease (mastery)

Total

Arterial blood gas

$\mathrm{PaO}_{2} \mathrm{mmHg}$

$\mathrm{PaCO}_{2} \mathrm{mmHg}$

$\mathrm{pH}$

$\mathrm{SaO}_{2} \%$

6MWD

$\mathrm{SpO}_{2}$ at rest \%

$\mathrm{SpO}_{2}$ at end of walk test \%

Distance $\mathrm{m}$

$$
\begin{gathered}
21 \\
1.4 \pm 1.0 \\
46 \pm 28 \\
58 \pm 20 \\
34 \pm 19 \\
42 \pm 18
\end{gathered}
$$

20

$18(90)$

$18(90)$

$17 \pm 10$

$19 \pm 5$

$35 \pm 8$

$21 \pm 5$

$92 \pm 17$

$$
\begin{gathered}
49.3 \pm 7.7 \\
36.9 \pm 5.4 \\
7.41 \pm 0.03 \\
82 \pm 8 \\
89 \pm 5 \\
80 \pm 9 \\
306 \pm 118
\end{gathered}
$$

Tobacco group

p-value

22

$1.2 \pm 0.9$

0.73

$30 \pm 18 \quad 0.03$

$46 \pm 19 \quad 0.02$

$24 \pm 13 \quad 0.10^{+}$

$33+14 \quad 0.07$

21

$16(76)-0.23$

$15(71) \quad 0.13$

$14 \pm 8 \quad 0.19$

$19 \pm 5 \quad 0.96$

$39 \pm 8 \quad 0.58$

$24 \pm 4 \quad 0.04^{+}$

$93 \pm 17 \quad 0.74$

$52.5 \pm 4 \quad 0.11$

$33.1 \pm 4 \quad 0.01$

$\begin{array}{ll}7.42 \pm 0.04 & 0.33\end{array}$

$87 \pm 4 \quad 0.01$

$92 \pm 3 \quad 0.07$

$84 \pm 4 \quad 0.04$

$307 \pm 152 \quad 0.98$

\begin{tabular}{|c|c|c|c|}
\hline & Biomass group & Tobacco group & p-value \\
\hline \multicolumn{4}{|l|}{ Emphysema measurements } \\
\hline Radiologist emphysema score & $0.67 \pm 0.80$ & $2.33 \pm 1.53$ & 0.0001 \\
\hline$\%$ LAA $<950 \mathrm{HU}$ at inspiratory scan & $19.28 \pm 10.65$ & $27.07 \pm 10.24$ & 0.02 \\
\hline Size of emphysematous spaces (D) & $2.57 \pm 0.56$ & $2.07 \pm 0.33$ & 0.002 \\
\hline \multicolumn{4}{|l|}{ Airways measurements } \\
\hline Radiologist air trapping score & $2.60 \pm 0.82$ & $1.52 \pm 1.12$ & 0.006 \\
\hline$\%$ LAA $<856 \mathrm{HU}$ at expiratory scan & $54.00 \pm 13.69$ & $56.60 \pm 15.26$ & 0.57 \\
\hline Square root of wall area at lumen perimeter $=10 \mathrm{~mm}$ & $4.48 \pm 0.34$ & $4.33 \pm 4.17$ & 0.17 \\
\hline Airway wall area percentage & $79.07 \pm 3.61$ & $77.91 \pm 3.76$ & 0.31 \\
\hline CT lung density ratio & $1.18 \pm 0.17$ & $1.34 \pm 0.19$ & 0.004 \\
\hline
\end{tabular}

Data are presented as mean \pm SD, unless otherwise stated. mMRC: modified Medical Research Council dyspnoea scale; SGRQ: St George's Respiratory Questionnaire; $\mathrm{PaO}_{2}$ : arterial oxygen tension; $\mathrm{PaCO}_{2}$ : arterial carbon dioxide tension; $\mathrm{SaO}_{2}$ : arterial oxygen saturation; $\mathrm{SpO} \mathrm{O}_{2}$ : arterial oxygen saturation measured by pulse oximetry. ${ }^{\#}$ : higher values represent worse health status; " lower values represent worse health status; ${ }^{+}$: nonparametric test.

airways metrics after adjusting for covariates, the radiologists' rating showed worse air trapping in women exposed to biomass smoke. These results are consistent with the conclusions from the autopsy study by RIVERA et al. [6], and, to our knowledge, represent the first direct comparison of COPD phenotypes in comparably obstructed living individuals exposed to biomass versus tobacco smoke, using questionnaire, exercise tolerance, lung function and MDCT data.

The body of evidence linking biomass smoke exposure to COPD is growing. Hu et al. [21] conducted a meta-analysis based on the literature published up to 2009 and reported that individuals exposed to biomass

\section{TABLE 3 Emphysema and small airways disease measurements}

Data are presented as mean \pm SD, unless otherwise stated. \%LAA: \% low attenuation area; CT: computed tomography. 
a)

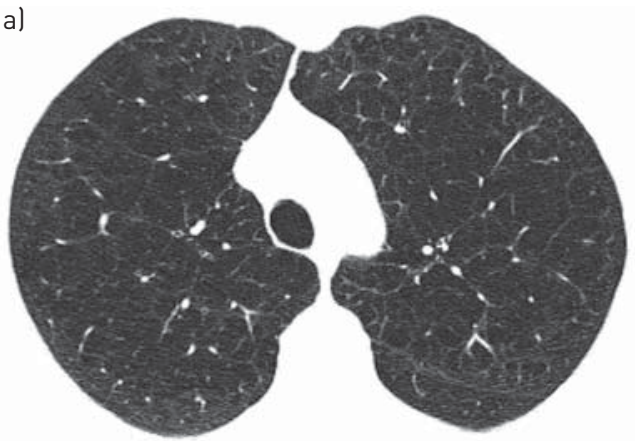

b)

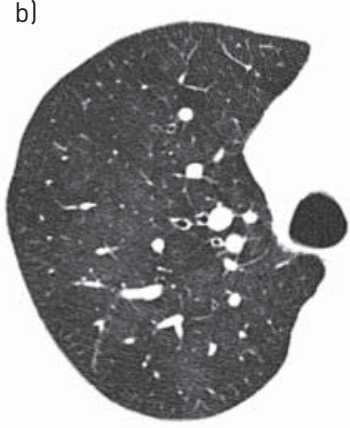

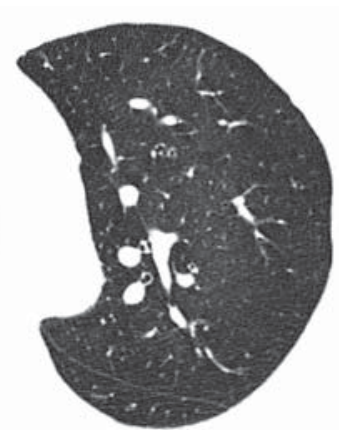

FIGURE 2 Inspiratory computed tomography (CT) scans from female participants with chronic obstructive pulmonary disease (COPD) from a) the tobacco group and b) of similar age and forced expiratory volume in $1 \mathrm{~s} \%$ predicted from the biomass group. a) severe centrilobular emphysema throughout the upper lobe can be seen. b) No obvious emphysematous spaces are visible, but her CT image shows airway wall thickening and patchy areas of decreased attenuation and vascularity, suggestive of small airways disease. Expiratory scans from this participant showed air trapping.

smoke were more than twice as likely to develop COPD than those who were not exposed (OR 2.44, 95\% CI 1.9-3.33). Po et al. [22] investigated the risk of COPD and other lung diseases due to biomass smoke in women and children and reported a similar odds ratio (2.40, 95\% CI 1.47-3.93). These findings are supported by a recent cross-sectional study by KURMI et al. [23], who reported reduced lung function, even in young adults, in those exposed to biomass smoke compared to nonexposed individuals, and by an earlier case-control study by PéREZ-PADILLA et al. [4], who compared biomass exposure levels in women with chronic bronchitis, chronic airflow obstruction or both to women who had other lung disease and healthy individuals. They found that participants with chronic bronchitis and airflow obstruction were 14 times more likely to have been exposed to wood-smoke, at similar levels as our subjects, compared to healthy individuals.

Less is known about the pathophysiology of COPD due to biomass smoke. Much of our knowledge of COPD today results from extensive research on the effects of tobacco smoke on the airways and lung parenchyma. Tobacco smoke exposure leads to decreases in expiratory flow and COPD by two distinct pathophysiological processes: the emphysematous destruction of the lung parenchyma, and/or narrowing and obliteration of the small peripheral airways [24]. Previous work on the pathophysiological changes related to biomass smoke exposure has not specifically addressed COPD phenotypes of emphysema or airway disease. For example, ARSLAN et al. [25] and KARA et al. [26] assessed the effects of biomass smoke and reported CT evidence of fibrotic bands and peribronchovascular thickening, yet did not focus on COPD.

Our study shows that women with tobacco exposure had more emphysema, while those with biomass smoke exposure had more air trapping as detected by radiologists, and worse symptoms, activities and mastery scores on the SGRQ and the CRQ. Although the radiologists' scoring and health status measures indicated more airway involvement in the biomass group, the quantitative CT measures of the airway dimensions and air trapping were not different between the two groups after adjustment for covariates. The participants in our sample were relatively young (mean age 69 years), at GOLD stage 2 and were not severely limited on their 6-min walk test. It is possible that, although radiologists detected air trapping and participants reported increased symptoms in the biomass group, there were no measurable changes in their airway wall thickness and quantitative measures of air trapping at this stage of their disease process. In this study we used multiple different measures of "airways disease". Some metrics, such as the CT estimates of airway dimensions and the radiologists' estimates of bronchiectasis reflect structural remodelling of intermediate and larger airways, whereas the CT measures of gas trapping (\%LAA and CT lung density ratio) reflect the structure and function of the small airways whose measurements are beyond the range of resolution of CT scanning. Even gas exchange is a measure of the heterogeneity of small airway narrowing in that it is a reflection of ventilation-perfusion mismatching. Although we have previously shown that structural changes in the larger airways, visible on CT scans, reflect the airway dimensions of smaller membranous bronchioles [17], the different metrics may not be related to each other and may have different structural bases and functional effects.

Alternatively, there might be too much variation in these measurements to detect real differences with our sample size. In addition, several of the airway measures were no longer significant between the two groups after adjusting for height. One possible explanation is that some of the airway parameters are influenced by lung size and shorter women would have smaller lungs and therefore smaller airway wall dimensions. Another explanation is that differences were due to differences in lung development related to poor 
TABLE 4 Multivariable models predicting emphysema and airway variables

\section{Emphysema}

Radiologist score of emphysema severity

Biomass group $\quad-1.555$

Age $\quad 0.035$

FEV1 \% pred $\quad-0.024$

Height

0.026

\%LAA $<950 \mathrm{HU}$ at inspiratory scan

Biomass group

$-7.397$

Age

$-0.177$

FEV $1 \%$ pred

Height

$-0.242$

0.201

Size of emphysematous spaces (D)

Biomass group

0.457

Age

$-0.008$

FEV1 \% pred

0.012

Height

$-0.012$

$-2.466--0.643$

0.001

$-0.032-0.101$

$-0.054-0.007$

0.299

ways disease

$-0.053-0.105$

$\begin{array}{ll}-14.657--0.136 & 0.046\end{array}$

$-0.731-0.377 \quad 0.521$

$\begin{array}{ll}-0.486-0.002 & 0.052\end{array}$

$\begin{array}{ll}-0.407-0.809 & 0.507\end{array}$

Radiologist score of air trapping severity

Biomass group

0.868

Age

$-0.034$

$0.137-0.777$

0.006

$-0.032-0.017$

0.530

$0.001-0.022$

0.036

$-0.039-0.015$

0.373

FEV1 \% pred

Height

$-0.012$

$-0.025$

$0.135-1.601$

0.022

$-0.087-0.019$

0.200

$-0.037-0.013$

0.322

$\%$ LAA $<856 \mathrm{HU}$ at expiratory scan

$-0.089-0.038$

0.421

Biomass group

$-0.952$

0.053

$-12.006-10.102$

0.863

FEV1 \% pred

$-0.774-0.880$

0.898

$-0.006$

$-0.367-0.354$

0.972

Height

0.256

$-0.661-1.173$

0.575

Square root of wall area at lumen perimeter $=10 \mathrm{~mm}$

0.099

Biomass group

FEV $1 \%$ pred

$-0.006$

$-0.155-0.354$

0.435

$-0.026-0.013$

$-0.003$

$-0.011-0.006$

Height

$-0.007$

$-0.028-0.015$

0.522

Airway wall area percentage

Biomass group $\quad 0.504$

Age

0.504
-0.061

$-2.171-3.180$

0.705

FEV1 \% pred

$-0.266-0.143$

0.546

$-0.065-0.115$

0.581

Height

0.025

$-0.343-0.105$

0.289

CT lung density ratio

$\begin{array}{ll}-0.220-0.027 & 0.121\end{array}$

Biomass group

$-0.100$

$-0.002$

$-0.011-0.008$

0.121
0.718

FEV1 \% pred

0.002

Height

0.010

$-0.002-0.006$

0.412

0.047

FEV1: forced expiratory volume in $1 \mathrm{~s} ; \%$ LAA: \% low attenuation area; CT: computed tomography.

nutrition or low socioeconomic status. Since the women recruited for this study were all patients from INER, which is a hospital that serves the very low-income population of Mexico City, it is likely that the current socioeconomic status of the participants was similar. However, it is true that other developmental factors could have been different between the two groups and could have influenced the patients' height. Alternatively, the model may be overcorrected, in the sense that height is a surrogate for exposure and correcting for height may artificially remove any real differences.

The participants in both exposure groups had a high prevalence of hypoxaemia. This is common in patients with COPD who live in Mexico City due to the high altitude $(2420 \mathrm{~m})$. Healthy individuals typically have oxyhaemoglobin saturation and $\mathrm{PaO}_{2}$ values that are lower than individuals at sea level (typically $95 \%$ and $68 \mathrm{mmHg}$, respectively), and individuals with COPD often have even further reductions in their $\mathrm{PaO}_{2}$.

Several mechanisms may be responsible for the phenotypic differences between exposure groups observed in this study. First, although biomass smoke has many of the same constituents as tobacco smoke [27], the exact composition differs depending on the source of the fuel, the efficiency of combustion and the relative 
humidity. Although particle size can be similar in tobacco and biomass smoke [28, 29], differences in chemical composition could lead to different pathophysiological processes. Secondly, the age of onset of biomass exposure is different to that of tobacco smoke. Biomass exposure in rural villages can begin in utero, and individuals are often exposed throughout their lives, with women receiving the largest cumulative exposures. Biomass exposure is also associated with multiple acute respiratory infections in children [28]. The early exposure and repeated respiratory infections may alter the structure and function of the airway walls beginning at an early age, and may predispose biomass smoke-exposed individuals to a different COPD phenotype as adults, compared to tobacco smokers who may begin smoking at an older age. Thirdly, there are possible differences in the inhalation pattern of those exposed to biomass versus tobacco smoke. Individuals inhaling biomass smoke would use a consistent tidal breathing pattern. Conversely, cigarette smokers usually smoke in a two-phase pattern: first the smoke is drawn into the mouth without direct inhalation into the lungs, then there is pause, and finally the smoke is inhaled into the lungs with an additional volume of air [29]. Average inhalation volumes have been measured at approximately $25 \%$ of vital capacity, which is twice that of the average tidal volume [29]. The larger inhalation volume in cigarette smokers compared to those exposed to biomass smoke may draw smoke more deeply into the lungs and may increase the deposition of the tobacco smoke in the lung parenchyma, leading to an emphysemapredominant COPD phenotype.

\section{Limitations}

There is the possibility that ethnicity contributed to our observations of increased airway disease in the biomass smoke group and increased emphysema in the tobacco smoke group. Although all our participants were currently residing in Mexico City, many participants with biomass smoke exposure had lived in rural communities at the time of exposure. In Mexico, women in rural communities are often of indigenous descent, whereas those born in urban communities often have Spanish ancestry. Therefore the predisposition to a COPD phenotype could be contributed to by different genetic susceptibilities. It is difficult to separate the contributions of ethnicity to our results. It is unlikely that we could identify an indigenous rural population that was not exposed to biomass smoke to act as a comparison group. In addition, rural versus urban women would have differing exposures to other factors, including outdoor air pollution, nutrition and healthcare, which could affect the development of COPD. The women who were recruited to this study attended the national hospital for low-income residents, and therefore the current socioeconomic status between the groups was probably similar; nevertheless, we cannot assess the impact of other environmental and behavioural factors on the development of distinct COPD phenotypes. We assessed CT characteristics and did not have pathology specimens to corroborate our findings. Finally, biomass exposure from other sources may lead to a different pulmonary presentation.

\section{Conclusion}

To our knowledge, this is the first study that has shown differences in COPD phenotypes in living women with biomass versus tobacco smoke exposure using both computer-aided and expert evaluation of MDCT. Results from this study should motivate further investigation into the complex interaction between different smoke exposures and the pathophysiology of COPD.

\section{Acknowledgements}

We wish to acknowledge Anh-Toan Tran, Lauren Wierenga and Natasha Krowchuk (Dept of Radiology, University of British Columbia, Vancouver, Canada) for technical assistance with the CT analysis programme and data management.

\section{References}

1 Albalak R, Frisancho AR, Keeler GJ. Domestic biomass fuel combustion and chronic bronchitis in two rural Bolivian villages. Thorax 1999; 54: 1004-1008.

2 Dennis RJ, Maldonado D, Norman S, et al. Wood smoke exposure and risk for obstructive airways disease among women. Chest 1996; 109: Suppl. 3, 55S-56S.

3 Orozco-Levi M, Garcia-Aymerich J, Villar J, et al. Wood smoke exposure and risk of chronic obstructive pulmonary disease. Eur Respir J 2006; 27: 542-546.

4 Pérez-Padilla R, Regalado J, Vedal S, et al. Exposure to biomass smoke and chronic airway disease in Mexican women: a case-control study. Am J Respir Crit Care Med 1996; 154: 701-706.

5 Ramírez-Venegas A, Sansores RH, Pérez-Padilla R, et al. Survival of patients with chronic obstructive pulmonary disease due to biomass smoke and tobacco. Am J Respir Crit Care Med 2006; 173: 393-397.

6 Rivera RM, Cosio MG, Ghezzo H, et al. Comparison of lung morphology in COPD secondary to cigarette and biomass smoke. Int J Tuberc Lung Dis 2008; 12: 972-977.

7 Menezes AM, Victora CG, Pérez-Padilla R, et al. The PLATINO project: methodology of a multicenter prevalence survey of chronic obstructive pulmonary disease in major Latin American cities. BMC Med Res Methodol 2004; 4: 15.

8 Pérez-Padilla R, Regalado J, Vazquez Garcia JC. Reproducibilidad espirométrica y adecuacion a valores de referencia internacionales en trabajadores mexicanos demandando incapacidad [Reproducibility of spirometry in Mexican workers and international reference values]. Salud Publica de Mexico 2001; 43: 113-121. 
Enright PL, Sherrill DL. Reference equations for the six-minute walk in healthy adults. Am J Respir Crit Care Med 1998; 158: 1384-1387.

10 Borg G. Ratings of perceived exertion and heart rates during short-term cycle exercise and their use in a new cycling strength test. Int J Sports Med 1982; 3: 153-158.

11 Bestall JC, Paul EA, Garrod R, et al. Usefulness of the Medical Research Council (MRC) dyspnoea scale as a measure of disability in patients with chronic obstructive pulmonary disease. Thorax 1999; 54: 581-586.

12 Jones PW, Quirk FH, Baveystock CM, et al. A self-complete measure of health status for chronic airflow limitation: the St George's Respiratory Questionnaire. Am Rev Respir Dis 1992; 145: 1321-1327.

13 Guyatt GH, Berman LB, Townsend M, et al. A measure of quality of life for clinical trials in chronic lung disease. Thorax 1987; 42: 773-778.

14 Patel BD, Coxson HO, Pillai SG, et al. Airway wall thickening and emphysema show independent familial aggregation in chronic obstructive pulmonary disease. Am J Respir Crit Care Med 2008; 178: 500-505.

15 Gevenois PA, Zanen J, de Maertelaer V, et al. Macroscopic assessment of pulmonary emphysema by image analysis. J Clin Pathol 1995; 48: 318-322.

16 Coxson HO, Whittall KP, Nakano Y, et al. Selection of patients for lung volume reduction surgery using a power law analysis of the computed tomographic scan. Thorax 2003; 58: 510-514.

17 Nakano Y, Wong JC, de Jong PA, et al. The prediction of small airway dimensions using computed tomography. Am J Respir Crit Care Med 2005; 171: 142-146.

18 Busacker A, Newell JD Jr, Keefe T, et al. A multivariate analysis of risk factors for the air-trapping asthmatic phenotype as measured by quantitative CT analysis. Chest 2009; 135: 48-56.

19 Mets OM, Buckens CF, Zanen P, et al. Identification of chronic obstructive pulmonary disease in lung cancer screening computed tomographic scans. JAMA 2011; 306: 1775-1781.

20 Rabe KF, Hurd S, Anzueto A, et al. Global strategy for the diagnosis, management, and prevention of chronic obstructive pulmonary disease: GOLD executive summary. Am J Respir Crit Care Med 2007; 176: $532-555$.

21 Hu G, Zhou Y, Tian J, et al. Risk of COPD from exposure to biomass smoke: a metaanalysis. Chest 2010; 138: 20-31.

22 Po JY, FitzGerald JM, Carlsten C. Respiratory disease associated with solid biomass fuel exposure in rural women and children: systematic review and meta-analysis. Thorax 2011; 66: 232-239.

23 Kurmi OP, Devereux GS, Smith WC, et al. Reduced lung function due to biomass smoke exposure in young adults in rural Nepal. Eur Respir J 2013; 41: 25-30.

24 McDonough JE, Yuan R, Suzuki M, et al. Small-airway obstruction and emphysema in chronic obstructive pulmonary disease. N Engl J Med 2011; 365: 1567-1575.

25 Arslan M, Akkurt I, Egilmez H, et al. Biomass exposure and the high resolution computed tomographic and spirometric findings. Eur J Radiol 2004; 52: 192-199.

26 Kara M, Bulut S, Tas F, et al. Evaluation of pulmonary changes due to biomass fuels using high-resolution computed tomography. Eur Radiol 2003; 13: 2372-2377.

27 Bruce N, Perez-Padilla R, Albalak R. The Health Effects of Indoor Air Pollution Exposure in Developing Countries. Geneva, World Health Organization, 2002.

28 Naeher LP, Brauer M, Lipsett M, et al. Woodsmoke health effects: a review. Inhal Toxicol 2007; 19 : 67-106.

29 Bernstein D. A review of the influence of particle size, puff volume, and inhalation pattern on the deposition of cigarette smoke particles in the respiratory tract. Inhal Toxicol 2004; 16: 675-689. 